\title{
Evaluation of Residual Stresses using Ring Core Method
}

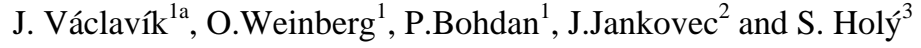 \\ ${ }^{1}$ ŠKODA VÝZKUM s.r.o., Dynamic testing laboratory, Tylova 1/57, 31600 Plzeň, Czech \\ Republic \\ ${ }^{2}$ ŠKODA VÝZKUM s.r.o., Computer modeling dept., Tylova 1/57, 31600 Plzeň, Czech Republic \\ ${ }^{3}$ Technical University in Prague, Mechanical Faculty, Technická 4, 16607 Prague, Czech \\ Republic
}

\begin{abstract}
The method for measuring residual stresses using ring-core method is described. Basic relations are given for residual stress measurement along the specimen depth and simplified method is described for average residual stress estimation in the drilled layer for known principal stress directions. The estimation of calculated coefficients using FEM is described. Comparison of method sensitivity is made with hole-drilling method. The device for method application is described and an example of experiment is introduced. The accuracy of method is discussed. The influence of strain gauge rosette misalignment to the evaluated residual stresses is performed using FEM.
\end{abstract}

\section{Introduction}

Identification of residual stresses in the structure is very important for estimation of the structure service or residual service life. In some cases the determination of residual stresses is used for controlling the manufacture process indirectly, which is the case of checking the core residual stresses of large forgings induced by heat treatment process through measuring the surface residual stresses.

However, the surface residual stresses are always influenced by stresses, induced due to rough turning, as there is difficult to apply the hole-drilling method to the rough structure of the nonmachined shaft. The influenced depth by turning is approximately $1 \mathrm{~mm}$, so there is the effort to measure the stress at least $2 \mathrm{~mm}$ below the surface. The allowable limit of residual stress is about $60 \mathrm{MPa}$ in a lot of mentioned cases.

The most widely used method for measuring residual stresses, the hole-drilling method, is sometimes used for this type of investigations. Procedures, sensitive to non-linear stress field, have to be used for measured data evaluation, which may be among others power series method, integral method or methods, using derivatives of relieved strains [1]. But these methods are not sensitive enough at required depths to give the stresses with satisfactory accuracy using conventionally produced strain gauge rosette diameters. This is the reason; why the ring-core method [2, 3] was implemented in ŠKODA VÝZKUM Ltd. This method allows measurements up to $6 \mathrm{~mm}$ depth, enables evaluation of stress profile along the depth and provides full relaxation of the stresses without undesirable stress concentration effects.

\footnotetext{
a e-mail : jaroslav.vaclavik@skodavyzkum.cz
} 


\section{Theory}

In the ring-core method, an annular grove is machined in the surface of the structural part with a crown-milling cutter [2]. The method utilizes the relaxation effect in the core to measure the macroscopic inherent stresses. The relieved strains are measured at the face of the core using threeelement rectangular rosette (see Figure 2) at common direction $a, b$ and $c$ and the residual stresses are calculated using derivatives of these strains with respect to the depth $z$ with the help of relaxation coefficients $K_{l}, K_{2}$. These coefficients are derived for uniaxial stress $\sigma_{l \text {, cal }}$, experimentally or with the help of FEM (1). The procedure for residual stress evaluation is following. The residual stresses in direction $a, b, c$ are first calculated according equations (2) to (4) and the principal stresses and their directions are obtained from them using known relations (5). The evaluation method is the same as used in [1] for hole-drilling method. The drawback of this method is the necessity of derivative evaluations with relative high accuracy.

$$
\begin{gathered}
K_{1}=\frac{E}{\sigma_{1, c a l}} \cdot \frac{d \varepsilon_{1, c a l}}{d z}, K_{2}=\frac{E}{v \cdot \sigma_{1, c a l}} \cdot \frac{d \varepsilon_{2, c a l}}{d z} \\
\sigma_{a}=\frac{E}{K_{1}^{2}-v^{2} \cdot K_{2}^{2}} \cdot\left(K_{1} \cdot \frac{d \varepsilon_{a}}{d z}-v \cdot K_{2} \cdot \frac{d \varepsilon_{c}}{d z}\right) \\
\sigma_{b}=\frac{E}{K_{1}^{2}-v^{2} \cdot K_{2}^{2}} \cdot\left[K_{1} \cdot \frac{d \varepsilon_{b}}{d z}-v \cdot K_{2} \cdot\left(\frac{d \varepsilon_{a}}{d z}-\frac{d \varepsilon_{a}}{d z}+\frac{d \varepsilon_{c}}{d z}\right)\right] \\
\sigma_{c}=\frac{E}{K_{1}^{2}-v^{2} \cdot K_{2}^{2}} \cdot\left(K_{1} \cdot \frac{d \varepsilon_{c}}{d z}-v \cdot K_{2} \cdot \frac{d \varepsilon_{a}}{d z}\right) \\
\sigma_{1,2}=\frac{\sigma_{a}+\sigma_{c}}{2} \pm \frac{1}{\sqrt{2}} \cdot \sqrt{\left(\sigma_{b}-\sigma_{a}\right)^{2}-\left(\sigma_{b}-\sigma_{c}\right)^{2}}, \varphi=\frac{1}{2} \arctan \frac{2 \cdot \sigma_{b}-\sigma_{a}-\sigma_{c}}{\sigma_{a}-\sigma_{c}}
\end{gathered}
$$

To performed production tests, where the principal directions are known, which is the case of large shafts, the simplified differential method is suitable. This method is based on the fact, that the residual stress may be assumed constant within the drilled layer. The principal stresses $\sigma_{l}$ and $\sigma_{2}$ in two perpendicular rosette directions $a$ and $c$ are calculated in the layer between the drilled depth $z$ and $2 \cdot z$ using measured strains differences at these directions between these drilling steps $\Delta \varepsilon_{a}, \Delta \varepsilon_{b}$. The relaxation coefficients $A$ and $B$, according (8) for this depth difference are used for stress calculation according relation (9)

$$
\begin{array}{cl}
\Delta \varepsilon_{a, c a l}=\varepsilon_{a, 2 z}-\varepsilon_{a, z}, & \Delta \varepsilon_{b, c a l}=\varepsilon_{b, 2 z}-\varepsilon_{b, z} \\
\Delta \varepsilon_{a, c a l}^{*}=\frac{\Delta \varepsilon_{a, c a l}}{\varepsilon_{1, c a l}} & \Delta \varepsilon_{b, c a l}^{*}=\frac{\Delta \varepsilon_{b, c a l}}{v \cdot \varepsilon_{1, c a l}} \\
A=\frac{E \cdot \Delta \varepsilon_{a, c a l}^{*}}{\left(\Delta \varepsilon_{a, c a l}^{*}\right)^{2}-\left(v \cdot \Delta \varepsilon_{b, c a l}^{*}\right)^{2}} & B=\frac{E \cdot \Delta \varepsilon_{b, c a l}^{*}}{\left(\Delta \varepsilon_{a, c a l}^{*}\right)^{2}-\left(v \cdot \Delta \varepsilon_{b, c a l}^{*}\right)^{2}} \\
\sigma_{1}=A \cdot \Delta \varepsilon_{a}-B \cdot \Delta \cdot \varepsilon_{b}, & \sigma_{2}=A \cdot \Delta \varepsilon_{b}-B \cdot \Delta \cdot \varepsilon_{a}
\end{array}
$$




\section{Relaxation coefficients derivation using FEA}

The FE-simulation was performed using the PC-version of FE-software COSMOS/M, vers. 2.9. For both the pre-processing and post-processing the COSMOS/M module GeoStar has been utilized. The analyzed area was a block of size $100 \times 77 \times 24 \mathrm{~mm}$ (length $\times$ width $\times$ height). The one end of this block was fixed and the second one was loaded by a given force $F=225 \mathrm{kN}$ (stress $\times$ area) in the direction of the specimen main axis. The simulation of drilled core (inner radius $7 \mathrm{~mm}$, outer radius $9 \mathrm{~mm}$ ) was performed in the middle of the specimen's top surface. The Poisson's ratio for the calculation was chosen to be $\mu=0.3$ and elasticity modulus in tension $E=2.1 \cdot 10^{5} \mathrm{MPa}$ The FEmesh of the problem was build-up parametrically using COSMOS/M command language to study influence of different dimensions. The FE-mesh structure enables incremental removing of the material in the core-area. The location of strain gauges was also taken into account. The process of mesh creation consists of two main steps:

- the 2D mesh creation - the areas of core and strain-gauges are specified

- the $3 \mathrm{D}$ mesh creation - extrusion of the $2 \mathrm{D}$ mesh, here the lengths of the extrusion correspond to the mentioned depth increments.

Each strain gauge has been modelled using 7 fibres, that is 14 points for strain calculations. Average strain for all 7 fibres as well as strain for each strain fibre was calculated.

The number of elements on edges of parametrically meshed areas size in the parametric meshing area was calculated along mesh size on boundaries of the automatic meshed area. The used element type is SOLID (8-node solid elements with three translational degrees of freedom per node). The used integration type is the default 8 -node hybrid element - displacement and stress-based (mixed) formulation $(2 \times 2 \times 2$ integration points). The iterative PCG-solver was used to solve the linear elastic problem. The average strains computed from the virtual fibres of each strain-gauge were the results from these calculations. These values were used for evaluation of calibrating coefficients.

The FE analysis was created for following types of strain gage rosettes: TML FR-5-11-3LT and HBM XY11.

Series of relived strains $\varepsilon_{a}, \varepsilon_{b}, \varepsilon_{c}$ at given depth and have been calculated using FEA for above mentioned types of strain gage rosettes in steps of $0.5 \mathrm{~mm}$ to the final depth of $8 \mathrm{~mm}$. Calculated equivalent stresse during ring core drilling simulation at $1 \mathrm{~mm}$ depth is shown in Figure 1. For the illustration, the real strain gauge rosette glued on the core is given in Figure 2.

The coefficients $K_{1}, K_{2}$, calculated from relived strains according (1) for rosette TML FR-5-11$3 \mathrm{LT}$ are plotted in Figure 3. The same coefficients, calculated for hole-drilling method, rosette HBM $\mathrm{RY} 21$, hole $\varnothing 4$ are drawn in the same plot. Calculated relaxation constants $A, B$ for ring-core rosette TML FR-5-11-3LT are given in Figure 4 together for hole drilling rosette HBM RY21, hole $\varnothing 4 \mathrm{~mm}$ and $\varnothing 6 \mathrm{~mm}$ and for manually applied large rosette on mean diameter $D$ around the ring-core hole $d=18 \mathrm{~mm}$, with the same $d / D$ ratio as rosette HBM RY21.

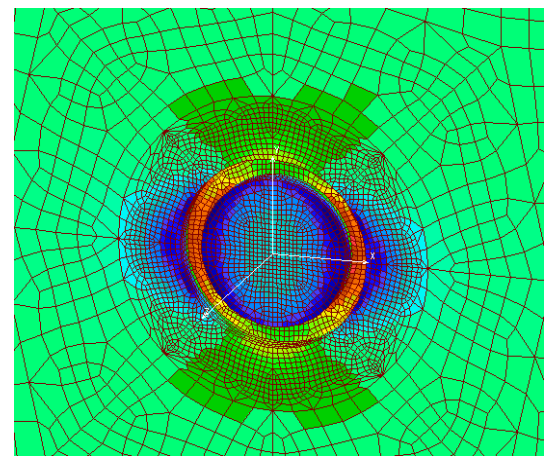

Fig. 1. Released stress field at $1 \mathrm{~mm}$ core depth

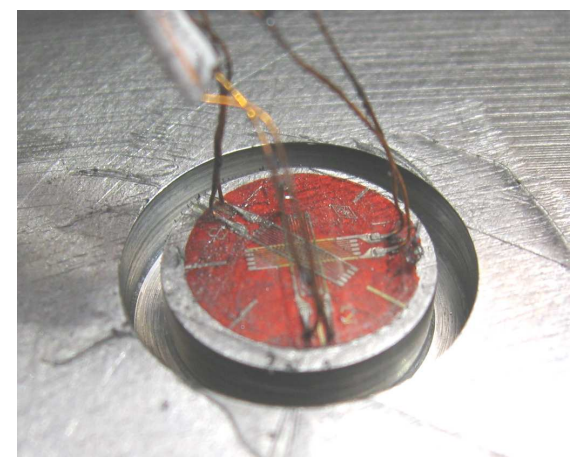

Fig. 2. Real strain gauge rosette TML FR-5-11-3LT 


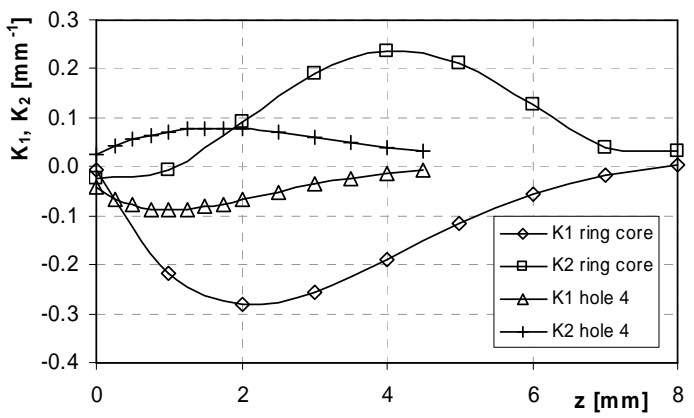

Fig. 3. Calculated relaxation constants $K_{l}, K_{2}$

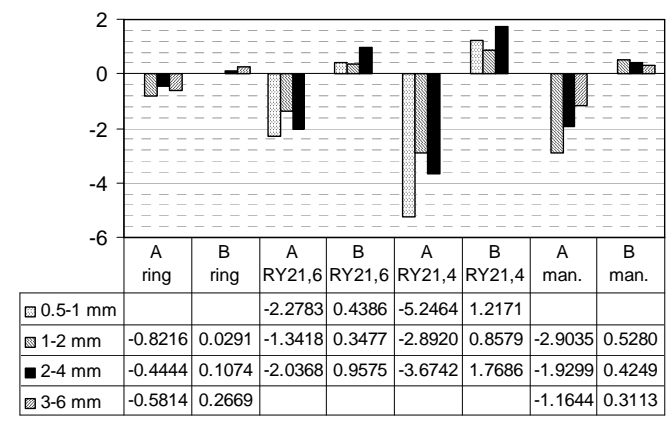

Fig. 4. Calculated relaxation constants $A, B$

\section{Comparison of ring-core with hole-drilling method}

Comparison of absolute relieved strains for both ring-core $(\varnothing 14 / \varnothing 18 \mathrm{~mm})$ and hole-drilling (rosette HBM RY21, Ø 4 and $\varnothing 6 \mathrm{~mm}$, HBM RY61, hole $\varnothing 1.5 \mathrm{~mm}$ ) methods for uniform uniaxial stress $60 \mathrm{MPa}$, is made in Fig. 5a and curve derivatives are given in Fig. 5b.
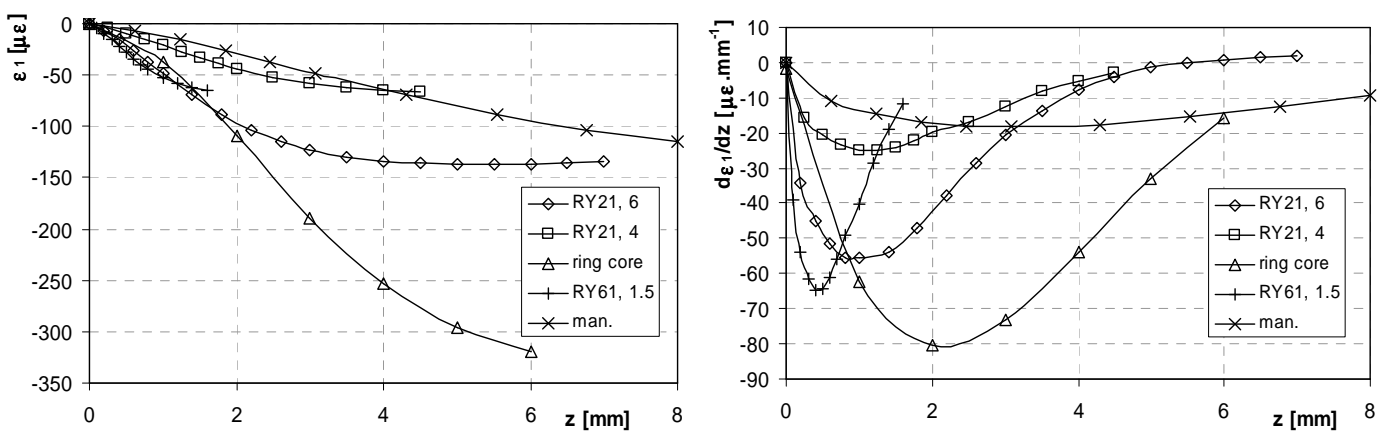

Fig. 5. Comparison of relieved strains and their derivatives for uniaxial stress $\sigma_{I}=60 \mathrm{MPa}$

The most sensitive depth for hole drilling method is $0,5 \mathrm{~mm}$ for small and $1 \mathrm{~mm}$ for large rosettes, where the derivatives have the maximum. The depth of this peak does not change with increasing the hole diameter. The highest sensitivity of ring-core method is over $2 \mathrm{~mm}$ depths. This fact is visible also from Figure 4, where the lowest value of $A, B$ gives the highest sensitivity of the method. Ring-core method is the best solution for residual stress measurement in the layer $2 \div 4 \mathrm{~mm}$, but for the layer $1 \div 2 \mathrm{~mm}$ the rosette RY21 with the hole $\varnothing 6 \mathrm{~mm}$ also can be recommended. Manually applied large rosette gives unexpected low sensitivity, comparable with RY21, Ø6 mm rosette. All charts are based on FEM calculations.

\section{Method application}

The ring-core milling device, used in ŠKODA VÝZKUM Ltd. is shown in Figure 6a. Special strain gauge rosette FR-5-11 TML with integrated leading wires in three-wire connection is applied in the centre of marked circle. The static measuring amplifier TC-31K, TML is used for relieved strain measurement and record. The annular groove $\varnothing 14 / \varnothing 18 \mathrm{~mm}$ is machined with special tubular milling cutter in steps of $0.5 \mathrm{~mm}$, the depth is controlled via dial gauge.

The application shown here served for checking the core residual stress of large rotor forging induced by heat treatment process through measuring the surface residual stresses. The goal was to 
separate the surface stresses, induced due to rough turning. An example of measured releived strains of rotor forging (material $25 \mathrm{Cr} 2 \mathrm{Ni} 4 \mathrm{MoV}$ ) after heat treatment, mean diameter $1100 \mathrm{~mm}$ (Figure 6b), is shown in Figure $7 \mathrm{~b}$. Evaluated principal stresses along the depth using polynomial approximation of released strain derivatives and the average stress at layers between $2 \mathrm{~mm}$ and $4 \mathrm{~mm}$ are plotted in Figure $7 \mathrm{~b}$. Here, the comparison is made with simplified method (column chart, marked 2-4). The comparison of data obtained from both ring-core and hole-drilling methods demonstrably show the higher sensitivity of ring-core method on real specimen.
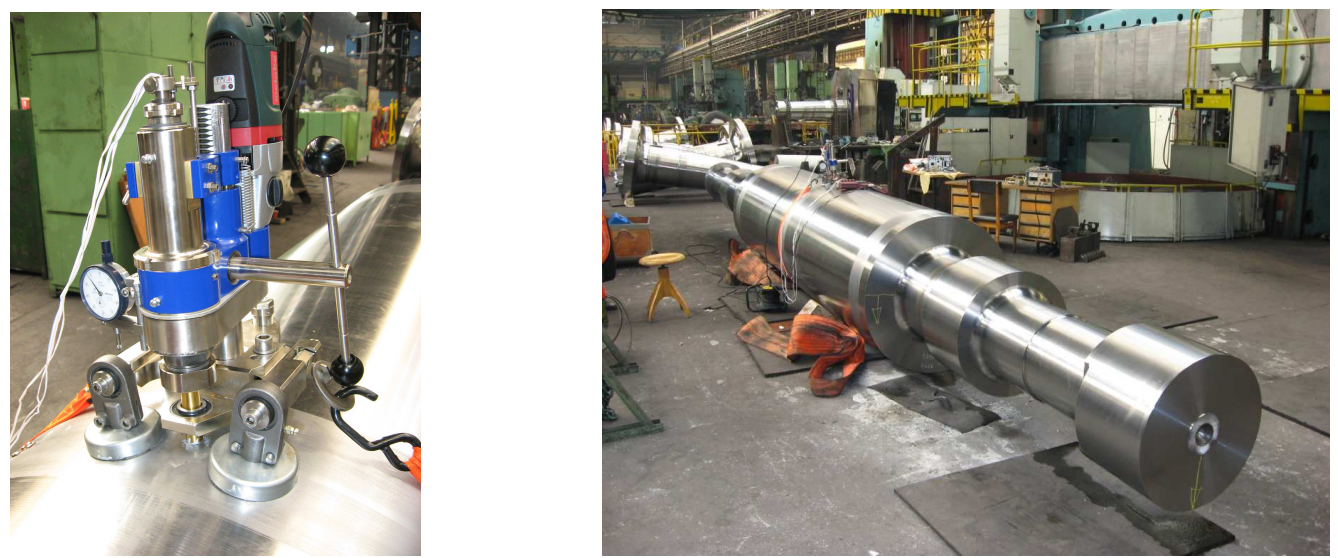

Fig. 6. Milling device for ring-core method and tested rotor forging
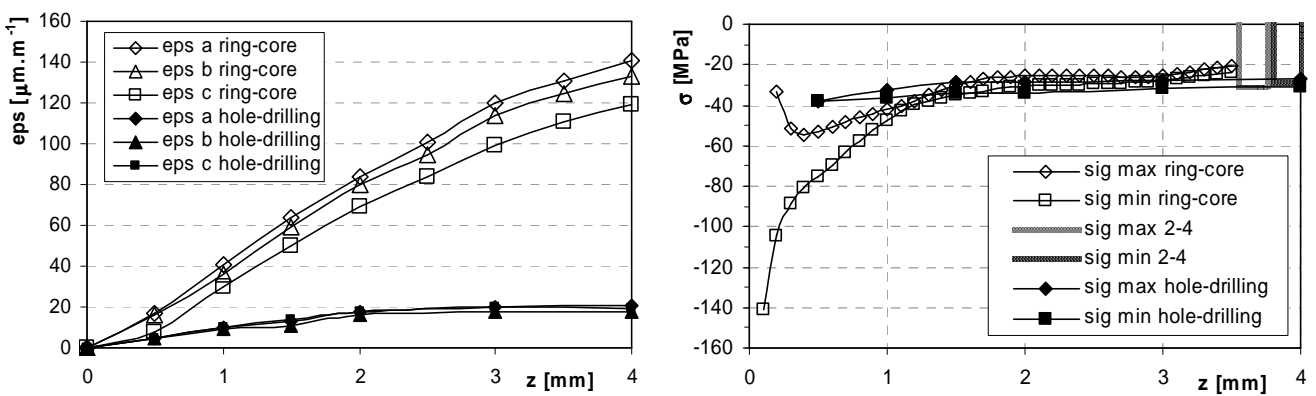

Fig. 7. Released rosette strains a) and evaluted principal residual stresses b) using ring-core and hole-drilling

\section{Accuracy of the method}

Standard uncertainty $u$ of residual stress, evaluated according (9), is given by following relations

$$
u=k \cdot \sqrt{u_{\varepsilon}^{2}+u_{K f}^{2}+u_{N}^{2}} \quad, \quad u_{\varepsilon}=\sqrt{\left(A^{2}+B^{2}\right) \cdot\left(2 \cdot u_{\varepsilon}^{2}\right)} \quad u_{K f}=\frac{\rho_{K f} \cdot K_{f}}{100 \cdot \sqrt{3}}
$$

where $k$ is the $n$-multiple of resulted standard deviation, which includes uncertainty of strain measurement $u_{\varepsilon}$, strain gauge $k$-factor $u_{k f}$ and complex uncertainty of other influences $u_{N}$, containg the missailgment of strain gauge rosette position, uncertainty of $A, B$ derivation and parasitic stresses, added during milling procedure.

The ifluence of strain gauge rosette FR-5-11 TML missalignment was studied at uniaxial stress state using FEM. Rosette was shifted from core centre in stress direction $x$, in perpendicular direction to the acting stress $y$ and in $45^{\circ}$ between them (xy) in steps of $0.25 \mathrm{~mm}$ up to $1.25 \mathrm{~mm}$. The highest value represents core overlap with the rosette of $0.25 \mathrm{~mm}$. Obtained results - relative stress 
deviations from nominal value - are given in Figures 1 to 3 . The systematic error due to the missaligmnet in $x$ and $y$ directions vs. milled depth is given in Figure 8. The error as the function of the missaligment in $x y$ direction is given in Figure 9. Plots for simplified method using coefficients $A, B$ are given for stress evaluated in depth intervals 1-2, 2-4 and 3-6 mm in Figure 10.

The stress value is most sensitive to the rosette missaligment in direction of main principle stress. The zero sensitivity to rosette missaligment is approximatelly at the depth of $2.5 \mathrm{~mm}$. For the simplified method when the residual stress is evaluated in the layer between 2 and $4 \mathrm{~mm}$ the error is less than $2 \%$ including the state, when the rosette underlayer tauches the edge of the core.
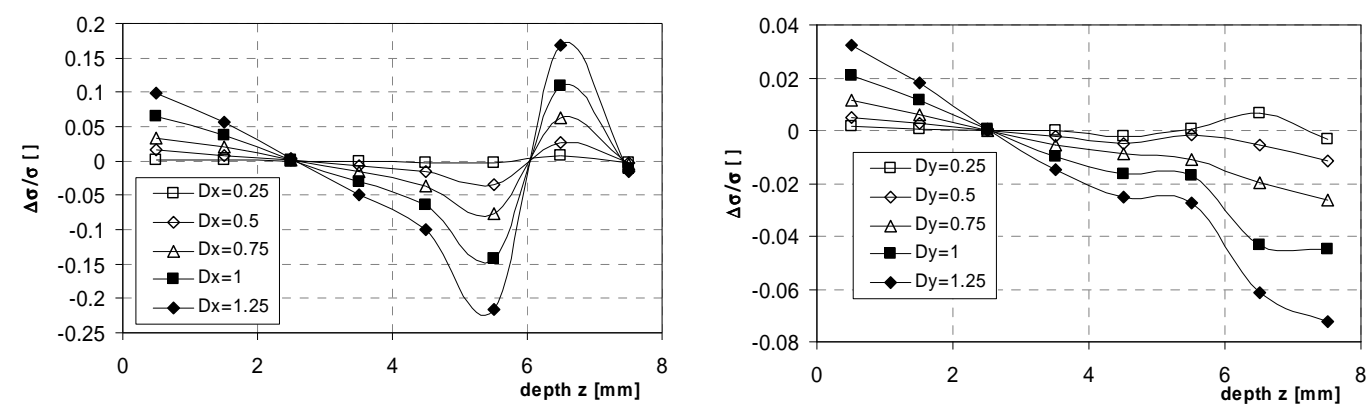

Fig. 8. Stress relative errors due to rosette misalignment in longitudinal and transversal directions

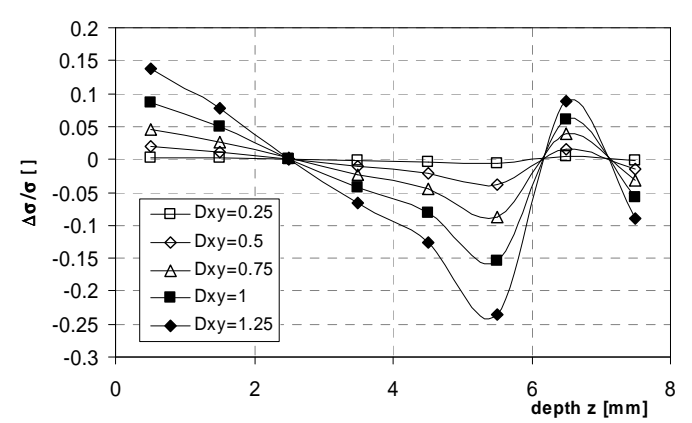

Fig. 9. Stress relative errors in directions of $45^{\circ}$

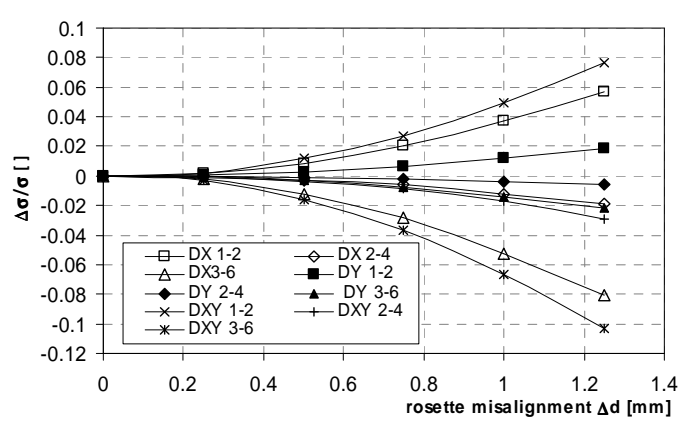

Fig. 10. Stress relative errors of simplified method

\section{Conclusion}

The ring core method was implemented in ŠKODA VÝZKUM Ltd. It is suitable for measurement of under-surface stresses, where the standard hole-drilling method is less sensitive. An improvement of mathematical model, experimental determination of calibrated coefficients, detailed sensitivity and reliability analysis is the object of next investigations. The work was supported by Ministry of Education Youth and Sports in the frame of Research plan MSM 4771868401.

\section{References}

1. T. Schwarz, T., H. Kockelmann, Die Bohrlochmetode - ein für viele Anwendungsbereiche optimales Verfahren zur experimentellen Ermittlung von Eigenspannungen, Messtechnische Briefe, 29, No.2, pp. 33-38, HBM, (1993)

2. W.Böhm, E.Stücker, H.Wolf, RAM, 4, 1 (1988)

3. J.Václavík, J.Jankovec, P.Bohdan, O.Weinberg, Residual stress measurement using ring core method, VYZ/TZ-54/76/2008, Research report, ŠKODA VÝZKUM s.r.o. (2008) 